\title{
Relationship Between High Aortic Pulse Pressure and Extension of Coronary Atherosclerosis in Males
}

\author{
J. PAŘENICA ${ }^{1 *}$, P. KALA ${ }^{1 *}$, J. JARKOVSKÝ ${ }^{2 *}$, M. POLOCZEK ${ }^{1}$, O. BOČEK ${ }^{1}$, \\ P. JEŘÁBEK ${ }^{1}$, P. NEUGEBAUER ${ }^{1}$, M. VYTISKA' ${ }^{1}$, I. PAŘENICOVÁ ${ }^{1}$, D. TOMČÍKOVÁ ${ }^{2}$, \\ M. PÁVKOVÁ GOLDBERGOVÁ ${ }^{\mathbf{3}}$, J. ŠPINAR ${ }^{\mathbf{1}}$
}

*These authors contributed equally to this article

${ }^{1}$ Cardiology Department, Faculty Hospital Brno, Brno, Czech Republic, ${ }^{2}$ Institute of Biostatistics and Analyses, Faculty of Medicine, Masaryk University, Brno, Czech Republic, ${ }^{3}$ Institute of Pathophysiology, Faculty of Medicine, Masaryk University, Brno, Czech Republic

Received January 5, 2010

Accepted June 28, 2010

On-line October 15, 2010

\section{Summary}

A high pulse pressure (PP) is a marker of increased artery stiffness and represents a well-established independent predictor for cardiovascular morbidity and mortality. The objective of the research was to determine whether invasively measured central aortic PP was related to the presence and severity of coronary artery disease. In total 1075 consecutive stable male patients undergoing diagnostic coronary angiography with a preserved left ventricular function were included. Diseased coronary vessel (DCV) was defined by the presence of $>50 \%$ stenosis. Men were divided into 3 groups according to the increased value of PP. The average PP in the tertiles was $47.8 \pm 7.1$ vs. $67.0 \pm 4.9$ vs. $91.3 \pm 12.8 \mathrm{~mm} \mathrm{Hg}(p<0,01)$. The significant differences of DCV was found among tertiles $(1.51 \pm 1.11$ vs $1.80 \pm 1.04$ vs. $1.99 \pm 0.98 \mathrm{DCV}, \mathrm{p}<0.01)$. Aortic PP together with age and hyperlipoproteinemia were found as factors with an independent relationship to DCV according to multivariate linear regression. In conclusions the increased value of aortic PP in the male population is independently connected with more severe atherosclerosis evaluated by the significant number of DCV.

\section{Key words}

Pulse pressure $\bullet$ Coronary artery disease $\bullet$ Atherosclerosis

\section{Corresponding author}

Jiri Parenica, Cardiology Department, Faculty Hospital Brno, Jihlavska 20, 62500 Brno, Czech Republic. Tel/fax: +420532232 651. E-mail: jiri.parenica@atlas.cz

\section{Introduction}

A high pulse pressure is a marker of increased artery stiffness and represents a well-established independent predictor for cardiovascular morbidity and mortality (Benetos et al. 2000, Domanski et al. 2002, Domanski et al. 2001, Millar et al. 1999) in hypertensives and even in those considered as having normal blood pressure (Benetos et al. 1998). High pulse pressure is associated with an increased risk of heart failure, independently of mean arterial pressure (MAP) and of the occurrence of acute myocardial infarction (Kostis et al. 2001). Few studies, involving a limited number of patients, have investigated the relation between aortic PP and angiographically documented diseased coronary vessels (DCV) (Jankowski et al. 2004, Nishijima et al. 2001) The values of PP are dependent on age and gender (Franklin et al. 1997, Franklin et al. 2001, Parenica et al. 2005). The objective of the research was to determine whether invasively measured aortic PP was related to the presence and severity of DCV in stable male patients with a preserved left ventricular function undergoing diagnostic coronary angiography.

\section{Methods}

Study population

From January 2001 to September 2003 in total 4,697 patients were referred to the cathlab of the 
Cardiology Department of Faculty Hospital Brno for diagnostic coronary angiography. Patients with acute myocardial infarction, those with aortic valve disease (aortic stenosis with peak to peak gradient $>25 \mathrm{~mm} \mathrm{Hg}$, aortic regurgitation greater than grade 1) and those with heart failure and/or ejection fraction (EF) $<45 \%$ were excluded from the analysis. Altogether 1075 consecutive men were included. Informed written consent was obtained from all subjects before participation in the trial. The study protocol complied with the Declaration of Helsinki and was approved by the local Ethics Committee.

\section{Definitions and study protocol}

Baseline characteristics (history, current symptoms and risk factors) and medication were established before examination. The presence of diabetes mellitus was defined as fasting blood glucose of $\geq 7 \mathrm{mmol} / \mathrm{l}$ or use of an antidiabetic drug or insulin. Hypercholesterolemia was defined as total plasma cholesterol $\geq 5 \mathrm{mmol} / 1$ or LDL cholesterol $\geq 2.6 \mathrm{mmol} / 1$ or being prescribed a lipid-lowering drug. Angina pectoris were assessed according to Canadian Cardiology Society classifications.

Invasive intra-aortic systolic blood pressure (SBP) and diastolic blood pressure (DBP) were measured using a fluid-filled catheter (4Fr pigtail catheter) in the ascending aorta with the patient in the supine position. Aortic PP was calculated as the difference between aortic SBP and aortic DBP, mean arterial pressure was calculated $[\mathrm{MAP}=\mathrm{DBP}+(\mathrm{SBP}-\mathrm{DBP}) / 3]$. Heart rate was recorded using electrocardiography monitoring. Diseased coronary vessel was defined by the presence of at least one $>50 \%$ reduction of intraluminal diameter on any of the coronary arteries (left main, left anterior descending, left circumflex, right coronary arteries), or the main branches with diameter $\geq 2.0 \mathrm{~mm}$. Significant left main artery stenosis was coded as two-vessel disease. Analysis of the coronary angiograms was made by the consensus of two out of seven experienced doctors. Ejection fraction was determined by the left ventricle angiography.

\section{Data analysis and statistics}

Data were reported as mean \pm standard deviation for continuous variables and percentage proportion for discrete variables. For testing differences between groups Student's t-test for continuous variables (all were normally distributed) and Pearson $\chi^{2}$-test for categorical variables were used. The differences in means of continuous variables among several groups of patients were analyzed using ANOVA followed by the post-hoc LSD test. Pearson's correlation coefficient was used to determinate relation between variables. Univariate and multivariate linear regression were used for adjusting PP and DCV values on influence of patients characteristics, comorbidities and medication. Preselection of variables based on univariate linear regression and expert opinion followed by backward stepwise algorithm were used for the definition of multivariate models.

\section{Results}

Clinical characteristics of the 3 groups (tertiles) according to the increased value of pulse pressure are listed in Table 1. Pulse pressure significantly correlated with systolic blood pressure (Pearson's correlation coefficient was 0.90), determination coefficient from linear regression model was 0.818 . Pearson's correlation coefficient between PP and diastolic blood pressure was 0.23 , the coefficient of determination was low -0.057 . No correlation was found between aortic pulse pressure and heart rate. Pulse pressure rose with age (Pearson's correlation coefficient was $0.41 ; \mathrm{p}<0.01$ ) (Figure 1 ), but the coefficient of determination was 0.17 , i.e. only $17 \%$ of variability of pulse pressure could be explained by age.

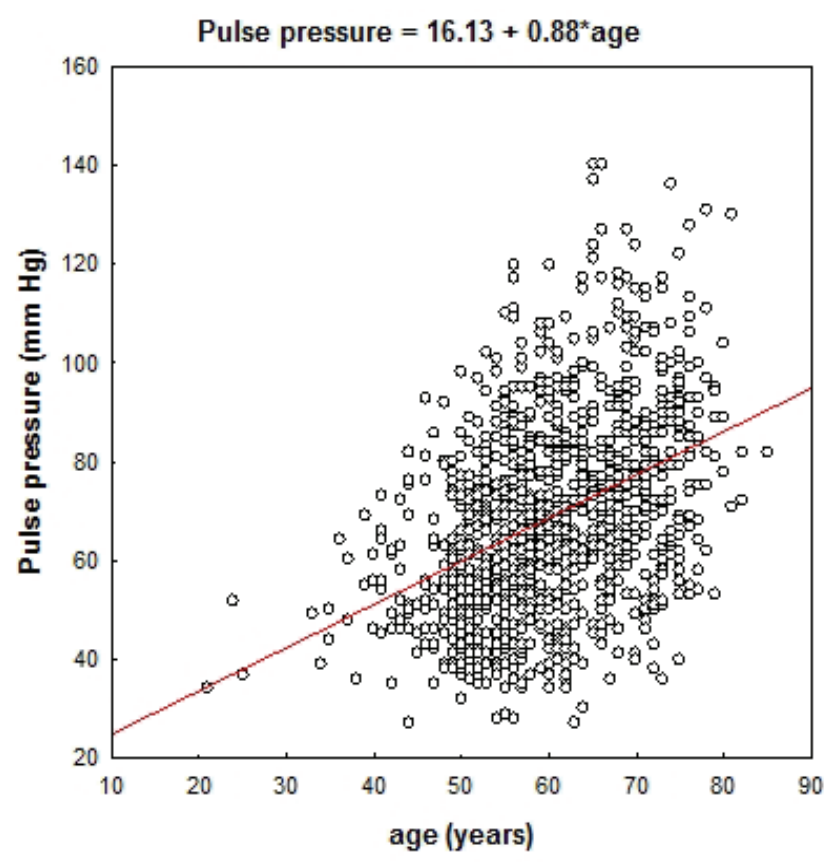

Fig. 1. Relation of pulse pressure and age. 
Table 1. Characteristics and medication of population according to the increasing pulse pressure.

\begin{tabular}{|c|c|c|c|c|c|}
\hline & $\begin{array}{c}\text { Totally } \\
(\mathrm{n}=\mathbf{1 0 7 5})\end{array}$ & $\begin{array}{l}1^{\text {st }} \text { tertile } \\
(n=343)\end{array}$ & $\begin{array}{l}2^{\text {nd }} \text { tertile } \\
(n=368)\end{array}$ & $\begin{array}{l}3^{\text {rd }} \text { tertile } \\
(n=364)\end{array}$ & \\
\hline Aortic PP (mm Hg) & $69.1 \pm 19.9$ & $47.8 \pm 7.1$ & $67.0 \pm 4.9$ & $91.3 \pm 12.8$ & $\mathrm{p}<0.01^{\mathrm{a}}$ \\
\hline Range of aortic PP (mm Hg) & $27-140$ & $27-58$ & $59-75$ & $76-140$ & \\
\hline Aortic systolic BP (mm Hg) & $138.0 \pm 24.5$ & $113.7 \pm 13.0$ & $135.9 \pm 11.4$ & $162.9 \pm 17.2$ & $\mathrm{p}<0.01^{\mathrm{a}}$ \\
\hline Aortic diastolic BP (mm Hg) & $68.9 \pm 10.4$ & $65.8 \pm 9.8$ & $68.9 \pm 10.1$ & $71.8 \pm 10.4$ & $\mathrm{p}<0.01^{\mathrm{a}}$ \\
\hline Aortic MAP (mm Hg) & $91.9 \pm 13.6$ & $81.8 \pm 10.4$ & $91.3 \pm 10.3$ & $102.2 \pm 11.5$ & $\mathrm{p}<0.01^{\mathrm{a}}$ \\
\hline Heart rate $\left(\mathrm{min}^{-1}\right)$ & $67.5 \pm 11.7$ & $68.3 \pm 11.6$ & $67.9 \pm 11.4$ & $66.5 \pm 12.0$ & $\mathrm{p}=0.32^{\mathrm{a}}$ \\
\hline Diabetes mellitus & $25.0 \%$ & $20.1 \%$ & $23.9 \%$ & $30.8 \%$ & $\mathrm{p}<0.01^{b}$ \\
\hline $\begin{array}{l}\text { History of cerebrovascular } \\
\text { disease }\end{array}$ & $4.2 \%$ & $0.9 \%$ & $5.4 \%$ & $6.0 \%$ & $\mathrm{p}<0.01^{\mathrm{b}}$ \\
\hline Smoking & $64.2 \%$ & $71.8 \%$ & $63.6 \%$ & $57.9 \%$ & $\mathrm{p}<0.01^{\mathrm{b}}$ \\
\hline Dyslipidemia & $54.1 \%$ & $51.3 \%$ & $58.7 \%$ & $51.9 \%$ & $\mathrm{p}=0.09^{\mathrm{b}}$ \\
\hline History of hypertension & $64.9 \%$ & $55.1 \%$ & $64.7 \%$ & $74.5 \%$ & $\mathrm{p}<0.01^{\mathrm{b}}$ \\
\hline & $(\mathrm{n}=761)$ & $(\mathrm{n}=249)$ & $(\mathrm{n}=254)$ & $(\mathrm{n}=258)$ & \\
\hline creatınıne $(\mu$ moll $)$ & $102.3 \pm 30.1$ & $97.5 \pm 14.1$ & $102.3 \pm 24.4$ & $108.2 \pm 42.9$ & $\mathrm{p}<0.01$ \\
\hline Ejection fraction LV (\%) & $60.3 \pm 7.7$ & $60.1 \pm 7.7$ & $60.4 \pm 7.9$ & $60.3 \pm 7.6$ & $\mathrm{p}=0.88^{\mathrm{a}}$ \\
\hline Diseased coronary vessels & $1.77 \pm 1.06$ & $1.51 \pm 1.114$ & $1.80 \pm 1.04$ & $1.99 \pm 0.98$ & $\mathrm{p}<0.01^{\mathrm{a}}$ \\
\hline \multicolumn{6}{|l|}{ Angina pectoris according to } \\
\hline CCSC & & & & & $\mathrm{p}<0.01^{\mathrm{b}}$ \\
\hline - Without angina pectoris & $44.5 \%$ & $49.6 \%$ & $43.8 \%$ & $40.4 \%$ & \\
\hline$-\operatorname{CCSC} 1$ & $6.5 \%$ & $8.2 \%$ & $6.3 \%$ & $5.2 \%$ & \\
\hline$-\operatorname{CCSC} 2$ & $28.8 \%$ & $26.8 \%$ & $30.2 \%$ & $29.4 \%$ & \\
\hline$-\operatorname{CCSC} 3$ & $14.0 \%$ & $8.7 \%$ & $14.1 \%$ & $19.0 \%$ & \\
\hline$-\operatorname{CCSC} 4$ & $1.3 \%$ & $1.2 \%$ & $0.5 \%$ & $2.2 \%$ & \\
\hline - Missing & $4.8 \%$ & $5.5 \%$ & $5.2 \%$ & $3.8 \%$ & \\
\hline Body Mass Index $\left(\mathrm{kg} / \mathrm{m}^{2}\right)$ & $28.4 \pm 3.8$ & $28.7 \pm 4.0$ & $28.3 \pm 3.8$ & $28.3 \pm 3.6$ & $\mathrm{p}=0.18^{\mathrm{a}}$ \\
\hline Weight $(\mathrm{kg})$ & $86.7 \pm 13.5$ & $89.5 \pm 14.5$ & $85.9 \pm 13.4$ & $84.9 \pm 12.1$ & $\mathrm{p}<0.01^{\mathrm{a}}$ \\
\hline Age (years) & $60.5 \pm 9.3$ & $56.0 \pm 9.2$ & $60.4 \pm 8.4$ & $64.8 \pm 8.2$ & $\mathrm{p}<0.01^{\mathrm{a}}$ \\
\hline \multicolumn{6}{|l|}{ Medication } \\
\hline $\begin{array}{l}\text { Peroral antidiabetics and/or } \\
\text { Insulin }\end{array}$ & $14.1 \%$ & $8.8 \%$ & $12.2 \%$ & $20.9 \%$ & $\mathrm{p}<0.01^{\mathrm{b}}$ \\
\hline Fibrates & $9.2 \%$ & $8.2 \%$ & $10.3 \%$ & $9.1 \%$ & $\mathrm{p}=0.61^{\mathrm{b}}$ \\
\hline Statins & $42.5 \%$ & $36.7 \%$ & $47.3 \%$ & $43.1 \%$ & $\mathrm{p}=0.02^{\mathrm{b}}$ \\
\hline Diuretics & $23.4 \%$ & $23.6 \%$ & $21.7 \%$ & $25.0 \%$ & $\mathrm{p}=0.58^{\mathrm{b}}$ \\
\hline$A T_{2}$ blockers & $1.1 \%$ & $0.9 \%$ & $1.4 \%$ & $1.1 \%$ & $\mathrm{p}=0.83^{\mathrm{b}}$ \\
\hline$A C E$ inhibitors & $51.3 \%$ & $43.7 \%$ & $51.4 \%$ & $58.2 \%$ & $\mathrm{p}<0.01^{\mathrm{b}}$ \\
\hline Calcium antagonists & $22.9 \%$ & $18.1 \%$ & $22.3 \%$ & $28.0 \%$ & $\mathrm{p}=0.01^{\mathrm{b}}$ \\
\hline Nitrates & $57.5 \%$ & $47.8 \%$ & $60.6 \%$ & $63.5 \%$ & $\mathrm{p}<0.01^{\mathrm{b}}$ \\
\hline Beta-blockers & $70.6 \%$ & $68.2 \%$ & $70.4 \%$ & $73.1 \%$ & $\mathrm{p}=0.40^{\mathrm{b}}$ \\
\hline Digoxin & $4.7 \%$ & $5.0 \%$ & $4.4 \%$ & $5.0 \%$ & $\mathrm{p}=0.91^{\mathrm{b}}$ \\
\hline Antiplatelets & $87.4 \%$ & $84.8 \%$ & $85.9 \%$ & $91.2 \%$ & $\mathrm{p}=0.22^{\mathrm{b}}$ \\
\hline
\end{tabular}

${ }^{a}$ Analysis of variance, ${ }^{b}$ Goodness-of-fit test. PP, Pulse pressure; BP, Blood pressure; CCSC, Canadian Cardiology Society Classification; $\mathrm{AT}_{2}$, antagonist for type 2 of receptor for angiotensin II; ACE, angiotensin-converting enzyme 
Table 2. Univariate and multivariate linear regression to define medications with independent relationship to the pulse pressure.

\begin{tabular}{lcccccc}
\hline & Univariate & & & Multivariate including age & \\
& Coefficient & $\begin{array}{c}\text { Confidence } \\
\text { interval }\end{array}$ & $\mathbf{p}^{\mathbf{1}}$ & Coefficient & $\begin{array}{c}\text { Confidence } \\
\text { interval }\end{array}$ & $\mathbf{p}^{\mathbf{1}}$ \\
\hline Age & 0.876 & $0.759 ; 0.993$ & $<\mathbf{0 . 0 0 1}$ & 0.816 & $0.695 ; 0.936$ & $<\mathbf{0 . 0 0 1}$ \\
ACE-AT $T_{2}$ & 5.332 & $2.978 ; 7.687$ & $<\mathbf{0 . 0 0 1}$ & 2.521 & $0.324 ; 4.718$ & $\mathbf{0 . 0 2 5}$ \\
ACE & 5.311 & $2.957 ; 7.664$ & $<\mathbf{0 . 0 0 1}$ & - & & \\
A $T_{2}$ blockers & 3.624 & $-7.672 ; 14.920$ & 0.529 & - & & \\
Beta-blockers & 1.504 & $-1.088 ; 4.096$ & 0.255 & - & & \\
Fibrates & -0.703 & $-4.808 ; 3.402$ & 0.737 & - & & \\
Statins & 1.809 & $-0.590 ; 4.207$ & 0.139 & - & & \\
Diuretics & 1.307 & $-1.494 ; 4.108$ & 0.360 & - & & \\
Ca-blockers & 5.333 & $2.525 ; 8.140$ & $<\mathbf{0 . 0 0 1}$ & 3.485 & $0.894 ; 6.075$ & $\mathbf{0 . 0 0 8}$ \\
Nitrates & 5.899 & $3.524 ; 8.274$ & $<\mathbf{0 . 0 0 1}$ & 2.174 & $-0.096 ; 4.444$ & 0.060 \\
Digitalis & -0.684 & $-6.268 ; 4.900$ & 0.810 & - & & \\
Antiplatelets & 3.647 & $0.083 ; 7.211$ & $\mathbf{0 . 0 4 5}$ & 0.836 & $-2.479 ; 4.152$ & 0.621 \\
\hline
\end{tabular}

${ }^{1}$ test of statistical significance of regression coefficients of linear regression; statistically significant coefficients are given in bold

Table 3. Univariate and multivariate linear regression to define variables with independent relationship to the number of diseased vessels.

\begin{tabular}{|c|c|c|c|c|c|c|}
\hline & \multicolumn{3}{|l|}{ Univariate } & \multicolumn{3}{|l|}{ Multivariate } \\
\hline & Coefficient & $\begin{array}{c}\text { Confidence } \\
\text { interval }\end{array}$ & $\mathbf{p}^{1}$ & Coefficient & $\begin{array}{c}\text { Confidence } \\
\text { interval }\end{array}$ & $\mathbf{p}^{1}$ \\
\hline Age & 0.031 & $0.024 ; 0.037$ & $<0.001$ & 0.027 & $0.020 ; 0.034$ & $<0.001$ \\
\hline$B M I$ & -0.010 & $-0.027 ; 0.007$ & 0.233 & - & & \\
\hline Smoking & 0.062 & $-0.075 ; 0.199$ & 0.377 & - & & \\
\hline Diabetes & 0.165 & $0.019 ; 0.312$ & 0.027 & - & & \\
\hline$H L P$ & 0.129 & $0.002 ; 0.256$ & 0.047 & 0.172 & $0.050 ; 0.295$ & 0.006 \\
\hline Adjusted Pulse $P^{2}$ & 0.010 & $0.007 ; 0.014$ & $<0.001$ & 0.005 & $0.002 ; 0.009$ & 0.002 \\
\hline Adjusted Systolic BP & 0.004 & $0.001 ; 0.007$ & 0.003 & - & & \\
\hline Adjusted Diastolic BP ${ }^{2}$ & -0.015 & $-0.021 ;-0.009$ & $<0.001$ & - & & \\
\hline Adjusted Mean BP & -0.002 & $-0.006 ; 0.003$ & 0.489 & - & & \\
\hline
\end{tabular}

${ }^{1}$ test of statistical significance of regression coefficients of linear regression; statistically significant coefficients are given in bold; 2 adjusted for ACE-AT 2 , Beta-blockers, Fibrates, Statins, Diuretics, Ca-blockers, Digitalis

According to multivariate analysis ACE inhibitors and/or AT 2 blockers and Ca blockers modify the pulse pressure (Table 2). Smokers had lower PP (67.5 $\pm 19.5 \mathrm{~mm} \mathrm{Hg}$ vs. $72.5 \pm 19.5 \mathrm{~mm} \mathrm{Hg} ; \mathrm{p}<0.01)$ and a comparable average number of DCV (1.79 \pm 1.04 vs. $1.73 \pm 1.12 ; \mathrm{p}=\mathrm{NS})$, but after adjustment for age, the difference in PP was insignificant and they had a significantly higher number of diseased coronary vessels $(\mathrm{p}<0.01)$.
Patients with diabetes had higher PP $(73.7 \pm 20.2$ vs. $67.6 \pm 19.5 \mathrm{~mm} \mathrm{Hg} ; \mathrm{p}<0.01)$ and a significantly higher number of DCV (1.90 \pm 1.05 vs. $1.73 \pm 1.06$; $p=0.03)$; after adjustment for age, the difference in PP was still significant, but there was no significant difference in DCV.

Patients with hyperlipoproteinemia had comparable PP $(69.0 \pm 18.9$ vs. $69.2 \pm 20.9 \mathrm{~mm} \mathrm{Hg}, \mathrm{p}=\mathrm{NS})$ even after adjustment for age, but they had a significantly 
higher number of DCV $(1.83 \pm 1.03$ vs. $1.70 \pm 1.10$, $\mathrm{p}<0.05)$ even after adjustment for age $(\mathrm{p}<0.01)$.

Patients with a history of hypertension had a significantly higher pulse pressure $(71.8 \pm 19.8 \mathrm{~mm} \mathrm{Hg}$ vs. $64.1+19.0 \mathrm{~mm} \mathrm{Hg}$; $\mathrm{p}<0.01$ ) even after adjustment for age. After adjustment for age, there was no significant difference in DCV.

We found a statistically significant difference of DCV in tertiles according to increased PP $(p<0.01$; Table 1). To ensure an independent influence of pulse pressure on the number of diseased vessels without an influence of other possible factors, univariate and multivariate linear regression was done (Table 3). Values of PP, SBP, DBP and MAP adjusted for medication were used. Although there were found significant relationships between PP, SBP, DBP and number of DCV in univariate analysis, only PP together with age and hyperlipoproteinemia were revealed as factors with an independent relationship to DCV according to multivariate analysis.

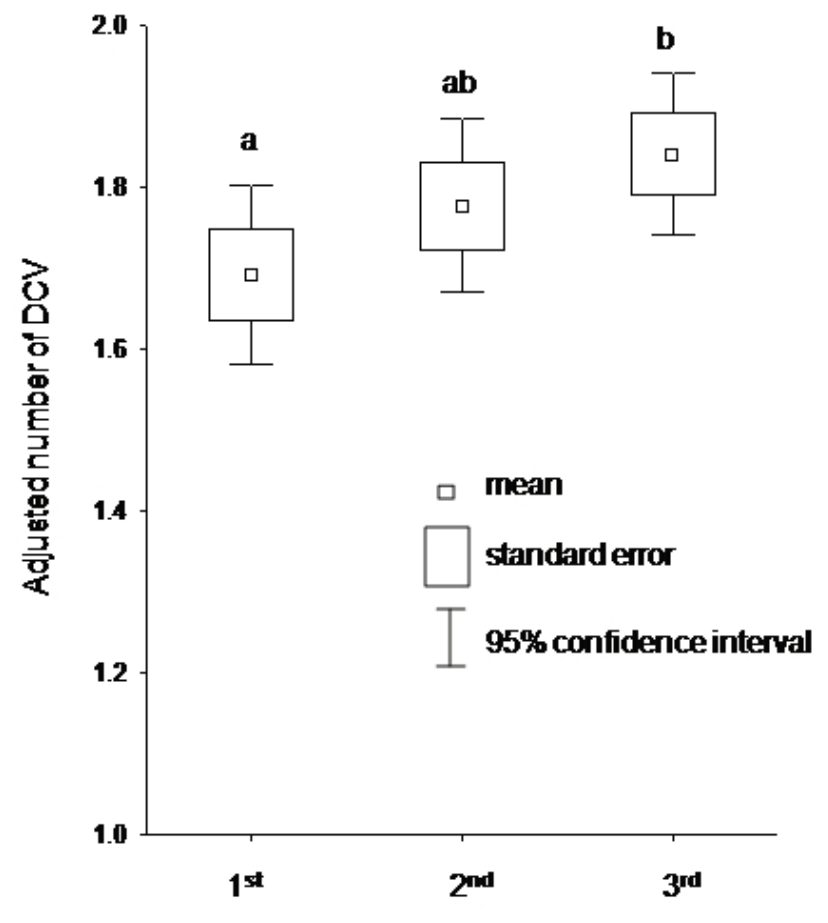

Tertiles of ad,usted pulse pressure

Fig. 2. Increasing number of significantly diseased coronary vessels in tertiles according to increasing pulse pressure adjusted to age and medication. Number of diseased vessels was adjusted for age and hyperlipoproteinemia. a,b - denotes statistically homogeneous groups revealed by LSD post hoc test

The Figure 2 demonstrates the difference of adjusted number of DCV according to the tertiles of the adjusted pulse pressure. The PP was adjusted for age and medications. The number of diseased vessels was adjusted for age and hyperlipoproteinemia as the independent variables found according to multiple linear regression. The adjusted pulse pressure was divided into tertiles and the adjusted number of diseased vessels was compared by ANOVA and post hoc LSD test. The differences in number of diseased vessels significantly differed among tertiles (ANOVA, $\mathrm{p}=0.049, \mathrm{~F}=3.16$, $\mathrm{df}_{1}=2, \mathrm{df}_{2}=1072$ ). Statistically significant differences in the number of the adjusted diseased vessels were found between $1^{\text {st }}$ tertile and $3^{\text {rd }}$ tertile.

\section{Discussion}

Only men were evaluated, because there is a significant difference between pulse pressure of men and women and the predictive value of pulse pressure for coronary artery disease was demonstrated above all for males (Franklin et al. 1997). It is necessary to evaluate the relation of PP and CAD for women separately.

Based on our best knowledge, the present study is so far the largest among those documenting an association between the value of invasively determined aortic PP and the extent of atherosclerosis of coronary arteries assessed from the number of diseased coronary vessels of men (Danchin et al. 2004). Our results are consistent with smaller studies previously presented. Philippe et al. (2002) represented in 99 patients that only invasive aortic pulse pressure, but not non-invasive brachial pulse pressure, and male gender were in a multiple regression analysis independently associated with the extent of coronary heart disease. Jankowski et al. (2004) found that pulse pressure, fractional systolic and diastolic blood pressure (systolic and diastolic blood pressure normalized to the mean blood pressure) of the ascending aorta was related to the risk of three-vessel disease in 445 patients (350 men) with coronary artery disease and a preserved left ventricular function. Weber et al. (2004) evaluated augmentation index and augmented pressure as manifestations of arterial stiffness in 465 men. Augmented pressure was defined as the difference between the second and the first systolic peak, augmentation index was augmented pressure expressed as a percentage of the calculated aortic pulse pressure. Augmentation index and augmented pressure were independent risk markers for premature coronary artery disease. More over there was demonstrated the aortic augmented pressure predicted adverse outcomes in patients with CAD independently of pulse pressure and 
other risk markers (Chirinos et al. 2005).

We did not find a significant relation between PP and heart rate. The rise of non-invasively established brachial PP with increasing heart rate, but not aortic PP, is in the result of an increase of PP amplification (Laurent et al. 2003).

We made univariate and then multivariate linear regression to detect a significant relationship between the previous treatment and the values of the pulse pressure. We revealed that there was an independent positive correlation of the aortic pulse pressure with previous treatment only by $\mathrm{ACE}$ inhibitors and/or $\mathrm{AT}_{2}$ blockers and $\mathrm{Ca}$ blockers. This result can be explained by the fact that the patients with high pulse pressure had more severe hypertension and they were more often treated by these drugs (subjects in the $3^{\text {rd }}$ tertile used more often ACE inhibitors, $\mathrm{Ca}$ antagonists, nitrates and statins and more often they had a history of hypertension and in average more severe symptoms of angina pectoris). Our results did not assess the direct effect of the drugs on the aortic PP. Published data about the effect of antihypertensive drug classes on brachial PP are not unique (Chang et al. 2003, Cushman et al. 2001); besides this, individual antihypertensive classes have a different effect on brachial and central pulse pressure (Morgan et al. 2004). CAFE study (a sub study of the ASCOT trial, which compared the active treatments based on calcium antagonist amlodipine with or without perindopril with treatment based on beta-blocker atenolol) demonstrated clearly that beta-blockers do not lower central systolic and pulse pressure as much as calcium antagonists (Williams et al. 2006).

It was interesting to find relationship between aortic pulse pressure and the number of diseased coronary vessels independently on age. Based on published prospective studies in patients $<50$ years of age, brachial diastolic blood pressure was the strongest predictor of coronary heart disease risk, age 50 to 59 years was a transition period when all 3 blood pressure indexes were comparable predictors and from 60 years of age on, diastolic blood pressure was negatively related to coronary heart disease risk so that brachial pulse pressure became superior to systolic blood pressure (Franklin et al. 2001).

Arterial stiffness, which leads to higher pulse pressure, has deleterious effects on left ventricular afterload, increases left ventricular mass, decreases coronary perfusion and leads to increased cardiovascular morbidity and mortality in different populations. Our results confirming the relationship between the extension of atherosclerosis of coronary vessels and the value of PP could explain the possible sequence of higher cardiovascular mortality in patients with higher pulse pressure.

In conclusion, increasing value of central aortic pulse pressure in male population is connected to more severe atherosclerosis. According to multivariate analysis the pulse pressure, age and hyperlipoproteinemia were evaluated as independent factors with relationship to the number of significantly diseased coronary vessels.

\section{Conflict of Interest}

There is no conflict of interest.

\section{Acknowledgements}

This study was supported by a grant from Internal Grant Agency of Ministry of Health NR 9356-3/2007.

\section{References}

BENETOS A, RUDNICHI A, SAFAR M, GUIZE L: Pulse pressure and cardiovascular mortality in normotensive and hypertensive subjects. Hypertension 32: 560-564, 1998.

BENETOS A, ZUREIK M, MORCET J, THOMAS F, BEAN K, SAFAR M, DUCIMETIERE P, GUIZE L: A decrease in diastolic blood pressure combined with an increase in systolic blood pressure is associated with a higher cardiovascular mortality in men. J Am Coll Cardiol 35: 673-680, 2000.

CHANG JJ, LUCHSINGER JA, SHEA S: Antihypertensive medication class and pulse pressure in the elderly: analysis based on the Third National Health and Nutrition Examination Survey. Am J Med 115: 536-542, 2003.

CHIRINOS JA, ZAMBRANO JP, CHAKKO S, VEERANI A, SCHOB A, WILLENS HJ, PEREZ G, MENDEZ AJ: Aortic pressure augmentation predicts adverse cardiovascular events in patients with established coronary artery disease. Hypertension 45: 980-985, 2005.

CUSHMAN WC, MATERSON BJ, WILLIAMS DW, REDA DJ: Pulse pressure changes with six classes of antihypertensive agents in randomized, controlled trial. Hypertension 38: 953-957, 2001. 
DANCHIN N, BENETOS A, LOPEZ-SUBLET M, DEMICHELI T, SAFAR M, MOURAD JJ; ESCAPP INVESTIGATORS: Aortic pulse pressure is related to the presence and extent of coronary artery disease in men undergoing diagnostic coronary angiography: a multicenter study. Am J Hypertens 17: 129-133, 2004.

DOMANSKI MJ, SUTTON-TYRRELL K, MITCHELL GF, FAXON DP, PITT B, SOPKO G; THE BARI INVESTIGATORS: Determinants and prognostic information provided by pulse pressure in patients with coronary artery disease undergoing revascularization (The Balloon Angioplasty Revascularization Investigation - BARI) Am J Cardiol 87: 675-679, 2001.

DOMANSKI M, MITCHELL G, PFEFFER M, NEATON JD, NORMAN J, SVENDSEN K, GRIMM R, COHEN J, STAMLER J; MRFIT Research Group: Pulse pressure and cardiovascular disease-related mortality. Follow-up study of the Multiple Risk Factor Intervention Trial (MRFIT). JAMA 287: 2677-2683, 2002.

FRANKLIN SS, GUSTIN W 4TH, WONG ND, LARSON MG, WEBER MA, KANNEL WB, LEVY D: Hemodynamic patterns of age-related changes in blood pressure: the Framingham Heart Study. Circulation 96: 308-315, 1997.

FRANKLIN S, LARSON MG, KHAN SA, WONG ND, LEIP EP, KANNEL WB, LEVY D: Does the relation of blood pressure to coronary heart disease risk change with aging? The Framingham Heart Study. Circulation 103: 1245-1249, 2001.

JANKOWSKI P, KAWECKA-JASZCZ K, BRYNIARSKI L, CZARNECKA D, BRZOZOWSKA-KISZKA M, POSNIK-URBANSKA A, KOPEC G, DRAGAN J., KLECHA A, DUDEK D: Fractional diastolic and systolic pressure in the ascending aorta are related to the extent of coronary artery disease. Am J Hypertens 17: 641646, 2004.

JANKOWSKI P, KAWECKA-JASZCZ K, CZARNECKA D, BRZOZOWSKA-KISZKA M, STYCZKIEWICZ K, STYCZKIEWICZ M, POŚNIK-URBAŃSKA A, BRYNIARSKI L, DUDEK D: Ascending aortic, but not brachial blood pressure-derived indices are related to coronary atherosclerosis. Atherosclerosis 176: 151-155, 2004.

KOSTIS JB, LAWRENCE-NELSON J, RANJAN R, WILSON AC, KOSTIS WJ, LACY CR: Association of increased pulse pressure with the development of heart failure in SHEP. Systolic Hypertension in the Elderly (SHEP) Cooperative Research Group. Am J Hypertens 14: 798-803, 2001.

LAURENT P, ALBALADEJO P, BLACHER J, RUDNICHI A, SMULYAN H, SAFAR ME: Heart rate and pulse pressure amplification in hypertensive subjects. Am J Hypertens 16: 363-370, 2003.

MILLAR JA, LEVER AF, BURKE V: Pulse pressure as a risk factor for cardiovascular events in the MRC Mild Hypertension Trial. J Hypertens 17: 1065-1072, 1999.

MORGAN T, LAURI J, BERTRAM D, ANDERSON A: Effect of different antihypertensive drug classes on central aortic pressure. Am J Hypertens 17: 118-123, 2004.

NISHIJIMA T, NAKAYAMA Y, TSUMURA K, YAMASHITA N, YOSHIMARU K, UEDA H, HAYASHI T, YOSHIKAWA J: Pulsatility af ascending aortic blood pressure waveform is associated with an increased risk of coronary heart disease. Am J Hypertens 14: 469-473, 2001.

PARENICA J, PINKOVA L, LUDKA O, FRANA P, NEMCOVA H, SPINAR J: Pulse pressure in the young population assessed by 24-hour ambulatory blood pressure monitoring and its relationship to metabolic and anthropometric values. (in Czech) Vnitř Lék 2: 123-130, 2005.

PHILIPPE F, CHEMALY E, BLACHER J, MOURAD J-J, DIBIE A, LARRAZET F, LABORDE F, SAFAR ME: Aortic pulse pressure and extent of coronary artery disease in percutaneous transluminal coronary angioplasty candidates. Am J Hypertens 15: 672-677, 2002.

WEBER T, AUER J, O'ROURKE MF, KVAS E, LASSNIG E, BERENT R, EBER B: Arterial stiffness, wave reflections, and the risk of coronary artery dinase. Circulation 109: 184-189, 2002.

WILLIAMS B, LACY PS, THOM SM, CRUICKSHANK K, STANTON A, COLLIER D, HUGHES AD, THURSTON H, O'ROURKE M; CAFE INVESTIGATORS: Differential impact of blood pressure lowering drugs on central aortic pressure and clinical outcomes: principal results of the Conduit Artery Function Evaluation (CAFE) study. Circulation 113: 1213-1225, 2006. 